
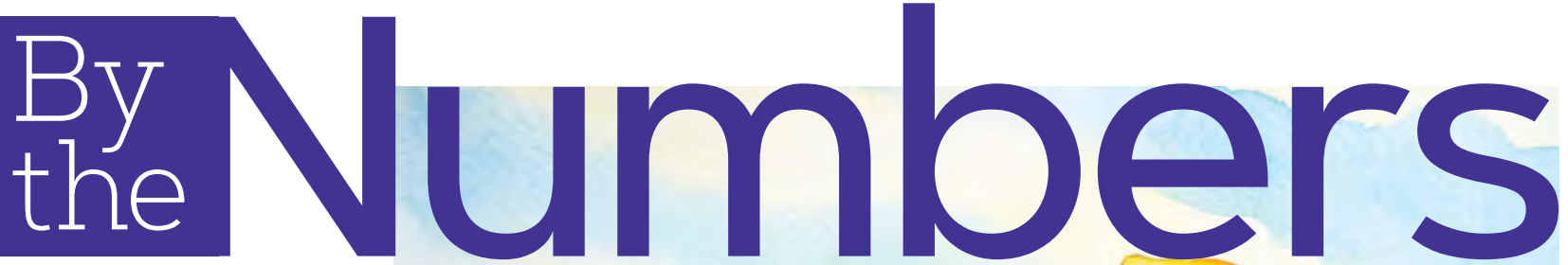

\title{
Mental health challenges
}

\section{JMU mirrors the nation}

Mental health concerns affect many of us, and college students are no different. In fact, the number of JMU students seeking help from the JMU Counseling Center is up almost 200 percent since 2000 . This spike in the need for mental health assistance includes anxiety and depression as the top two concerns.

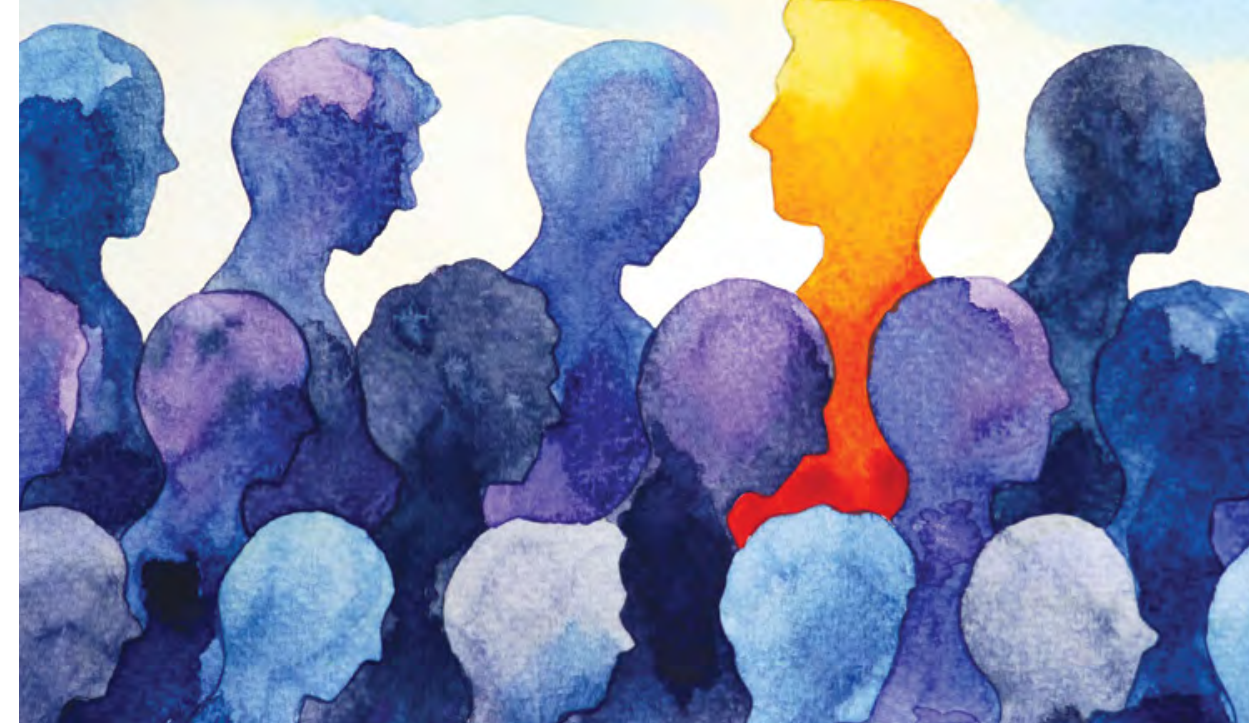

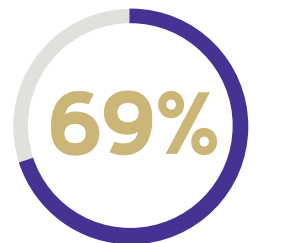

$69 \%$ of clients surveyed reported that because of Counseling Center services, they were more likely to stay at JMU.*

$27 \%$ reported that it "Did Not Apply."

\section{JMU Counseling Center Growth: 2000-17}

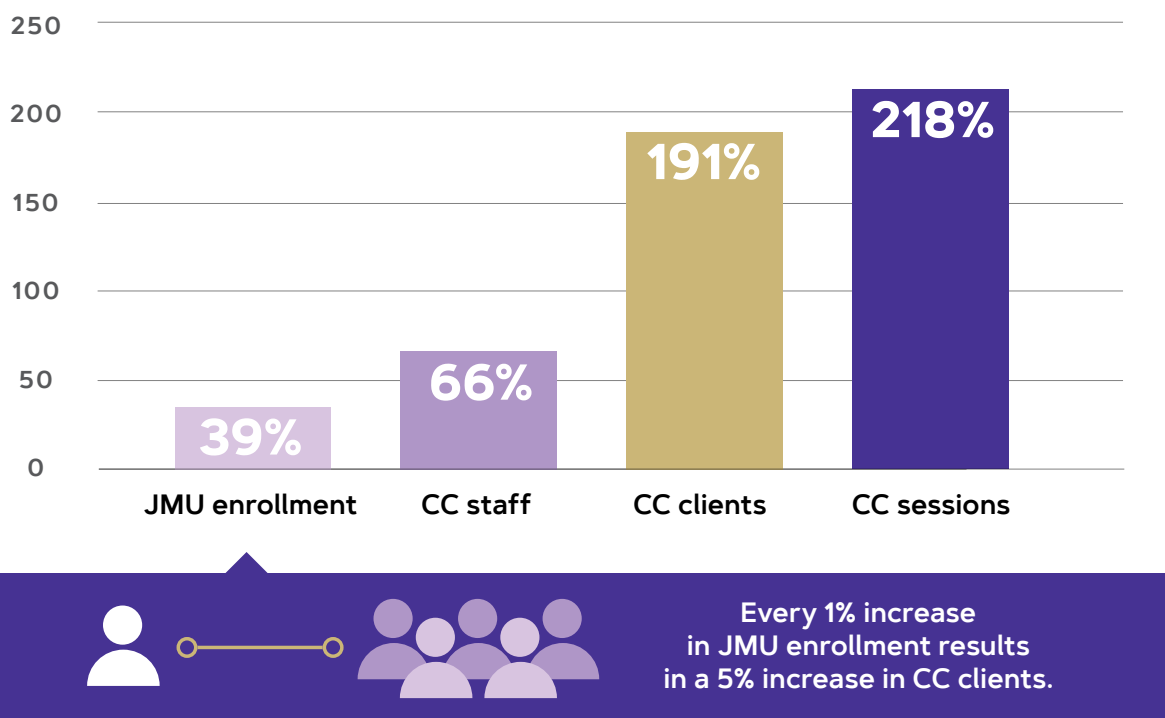

Of the Top 10 Impediments to Academic Success

1. Stress

2. Anxiety

3. Sleep issues

4. Depression

5. Cold/Flu

6. Work

7. Concern for troubled friend or family member

8. Extracurriculars

9. Internet \& Games

10. Relationships

are directly
related to
mental health
symptoms

are directly related to symptoms 